\title{
Colonialismo, Saberes e Fronteiras epistêmicas: algumas hipóteses à guisa de provocação (ou "algumas provocações à guisa de hipótese")
}

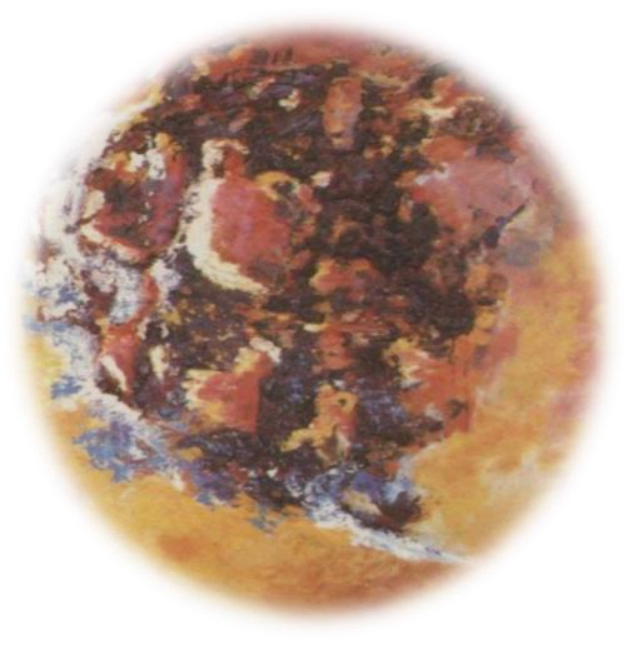

Estevão Rafael Fernandes ${ }^{1}$
Fabiano Gontijo ${ }^{2}$
Vico Melo $^{3}$
Michel Justamand $^{4}$

\section{Resumo}

Fazendo um apanhado geral de ideias relacionando o colonialismo acadêmico às potencialidades de se fazer pesquisa em regiões localizadas nas periferias do sistema hegemônico de (re)produção de conhecimentos, este texto pretende provocar reflexões sobre o papel desses espaços no jogo de forças da academia.

Palavras-chave: Hegemonia epistêmica. Fronteiras. Anticolonialismo.

1 Antropólogo, Doutor em Ciências Sociais pela Universidade de Brasília (2015). Professor no Departamento de Ciências Sociais da Universidade Federal de Rondônia. Email: estevaofernandes@gmail.com

2 Antropólogo, Doutor em Antropologia pela École des Hautes Études en Sciences Sociales, França (2000). Professor do Programa de Pós-Graduação em Antropologia da Universidade Federal do Pará. Bolsista de Produtividade em Pesquisa do CNPq. Email: fgontijo2@hotmail.com

${ }^{3}$ Doutor em Pós-Colonialismos e Cidadania Global pela Universidade de Coimbra (2016). Professor do Instituto de Humanidades e Letras da UNILAB. Email: vico.denis@hotmail.com

${ }^{4}$ Antropólogo, Doutor em Ciências Sociais (Antropologia) pela PUC-SP. (2007) Professor de Antropologia da UFAM em Benjamin Constant. Email micheljustamand@yahoo.com.br 
Este texto se pretende muito mais um arremedo de ideias provenientes de colegas de diferentes espaços academicamente situados nas bordas da academia hegemônica brasileira e mais um apanhado de ideias que venha a provocar, no sentido mais radical do termo, maiores reflexões sobre os desafios e vantagens de se produzir conhecimentos e articular saberes na academia, desde loci situados às margens dos grandes centros, do que um texto acadêmico em sentido estrito, cheio de citações falso-legitimadoras de autores à la mode, cheio de lições morais fantasiadas de discussões teóricas ou cheio de justificativas metodológicas pseudopós-tudo.

Partiremos, assim, das seguintes "hipóteses" (para alguns, “provocações"?).

Como primeira hipótese, indicamos que as políticas de expansão do ensino superior ao longo dos últimos anos possibilitou à academia incorporar, tanto em seus quadros quanto em suas salas de aula, um conjunto de atores e agentes que, até então, não teriam acesso à academia - ou melhor, aos quais era sistematicamente negado o acesso à academia. Esta incorporação, entretanto, ainda não se deu em espaços de poder, tais como agências de fomento, associações científicas e, mais além, nas relações cotidianas dentro das universidades. E, quando os atores ou agentes chegam (timidamente) aos (poucos) espaços de poder (a que são autorizados), não podem exercer o poder do ponto de vista de seus próprios saberes, sendo-lhes outorgado somente o exercício (diminuto) do poder dentro dos limites instituídos pelos discursos hegemônicos, dominantes ou coloniais/colonizadores. Neste sentido, o conhecimento ainda é produzido de e para sujeitos tradicionalmente hegemônicos e reproduz, assim, em grande parte, suas epistemologias e suas ontologias político-acadêmicas - e mesmo as questões relacionadas à manutenção dessa hegemonia se dão nos termos impostos por esses sujeitos, a partir dessas epistemologias e dessas ontologias. 


\section{Colonialismo, Saberes e Fronteiras epistêmicas}

Uma segunda hipótese é que a inclusão, o cabimento e a consolidação de outras formas de saber implicam, necessariamente, em reestruturação tanto das relações que, historicamente, marcam a distribuição de poder dentro da academia quanto, também, a reformulação da própria forma como o saber é compreendido, pulverizado e mantido.

Como terceira hipótese, pensamos que a consolidação de outros sistemas de conhecimentos na estrutura hegemônica de constituição de saberes na academia passa, frente ao recrudescimento dos discursos xenofóbicos, racistas e lgbtfóbicos no Brasil, por uma postura não apenas estritamente acadêmica mas, também, epistemopolítica.

Mesmo que, eventualmente, venha a se discordar dessas hipóteses no todo ou em parte - é importante notar que os caminhos apontados por elas nos levam a questionar lugares de enunciação bastante consolidados histórica, social e culturalmente na manutenção dos espaços acadêmicos no Brasil. Aqui, cabe destacar que os limites da proposta deste texto transcendem o universo das universidades, por razões elementares. A principal seria, justamente, a interrelação estreita entre saber e poder, apontada por pensadores clássicos e contemporâneos, desde Foucault até Wallerstein, passando por Walter Mignolo, Thiong'o e Achille Mbembe. E é aqui que entra nossa primeira crítica ao colonialismo: seu caráter de constituir epistemicamente e consolidar, politicamente, um conjunto de saberes a partir dos quais o único saber visto e aceito como legítimo é aquele que corrobora com o universo de possibilidades alcançado pelo polo hegemônico nas relações coloniais. Mesmo que esses conhecimentos possam vir a ser produzidos nas academias tradicionais (universidades e instituições de pesquisa), o colonialismo epistêmico tende a invisibilizá-los por estarem fora das fronteiras teórico-metodológicas euronorcentradas.

Isso quer dizer, na prática, que o saber que alcança visibilidade e legitimidade é aquele que, em seu âmago, subalterniza, aniquila ou ridiculariza todas as outras formas de saber. 
Tal ação se dá tanto em políticas editoriais e de distribuição de recursos (financeiros, humanos, materiais, etc.) quanto na forma como o poder é propagado, dentro e fora da academia. O sistema se fecha em torno de si mesmo, em um vórtice de autocitações, de reciprocidade de favores, de distribuição de influências e poderes dentro de círculos bem delimitados de modo a não incluir formas fronteiriças de conhecimento. Uma rápida olhada em editais de fomento, publicações de grandes editoras e revistas universitárias, assentos em comitês de conselhos científicos nos permite inferir, das duas uma: ou praticamente nada que se produza no eixo NorteNordeste merece figurar nestes espaços, ou há formas de relacionamento outras que regem a distribuição de poder nestes fóruns.

São regiões historicamente exploradas e para as quais o olhar da academia sempre se voltou como grandes laboratórios de pesquisa (falamos aqui, especificamente, no âmbito das ciências humanas; sabemos que para outras áreas do conhecimento as implicações destes argumentos seriam outras). É assim que, por exemplo, discentes e docentes de instituições de ensino superior do Pará ou de Rondônia se vangloriam com a "chance" de poderem fazer um estágio "sanduíche" ou pós-doutoral numa instituição de São Paulo ou de Santa Catarina, enquanto raramente se vêem discentes e docentes do eixo Centro-Sul fazendo tais tipos de estágios em instituições do Norte. É assim que, por mais um exemplo, as bancas de concurso públicos para a carreira docente ou de defesas de dissertações e teses defendidas nos Programas de Pós-Graduação das Regiões Norte e Nordeste são legitimadas pelos pares quando compostas por, pelo menos, um membro avaliador externo preferencialmente vinculado a alguma instituição do eixo Centro-Sul... Assim, Norte e Nordeste (e incluímos aqui centros periféricos dentro do eixo Centro-Sul, formando um grande complexo fronteiriço de saberes) ainda não conseguiram se descolar, plenamente, de um modelo histórico ao qual foram submetidos. Isso nos leva a outra questão. 


\section{Colonialismo, Saberes e Fronteiras epistêmicas}

O sistema-periferia de saberes é subalternizado e invisibilizado por ser, historicamente, racializado? Nossa perspectiva é que sim. A narrativa da colonização é teleológica, com o colonizador operando como se fosse um narrador onisciente. Afinal, a locomotiva do conhecimento é o Centro-Sul, nosso "norte" epistêmico, mantendo relações históricas de colonialismo interno. Não apenas isso: o Centro-Sul epistêmico atingiu o nível mais alto do desenvolvimento, ensinando-nos desde o ensino médio, que graças aos braços de imigrantes brancos e de barões da indústria e do café adivinhem... brancos - foi possível atingir esse nível de progresso.

Já o Nordeste figura em torno da discussão sobre a construção da "nação brasileira" numa dialética da ambiguidade. Ao mesmo tempo em que se enaltece o seu passado histórico de bonança produzido pelos engenhos de cana de açúcar, através dos seus “senhores” brancos - há poucos anos isso seria facilmente visível em Recife, enquanto se trafegava em algumas avenidas com placas "informativas" exaltando os grandes senhores de engenho que contribuíram para o desenvolvimento de Pernambuco e do Nordeste. Por outro lado, esse mesmo passado histórico é quase que automaticamente criticado por ter sido responsável pelo “subdesenvolvimento" da região, devido à presença quase medieval desses mesmos engenhos, baseados em mão de obra negra escravizada e com indígenas "inaptos ao trabalho braçal" (todos já ouviram isso). A crítica, em si, reside muito mais na impossibilidade de qualquer "desenvolvimento" a partir da forte presença negra e indígena no processo colonial que na própria crítica à violência colonial promovida contra esses povos.

Enquanto isso, a Amazônia, equivalente a metade do País, aparece como uma nota de rodapé quando se fala em drogas do sertão - e nem sequer se lembram nossos contemporâneos que a Amazônia era uma outra colônia portuguesa, a do Maranhão e Grão-Pará, que só foi juntada à colônia brasileira após muita dificuldade entre os séculos XVIII e XIX, o que ajuda 
a entender melhor a grande disparidade ainda persistente nos modos de vida dessas regiões. Se, a esta altura, ao ler estas linhas, lhe passa pela cabeça que estas reflexões são fruto de um complexo de vira-latas ou coisa assim, a questão é justamente o contrário: a consciência dessa espoliação de si mesmo é o primeiro passo para uma atitude anticolonial, revolucionária e libertadora.

O racismo permanece. A colonização permanece. Ao se negar espaço a esses outros epistêmicos, nega-se-lhes espaço para que tomem consciência de si, para resistência, para suas próprias subjetividades, acionalidades, emocionalidades e reatividades - para suas ontologias libertárias.

Uma vez que sua visão de si está relegada a um segundo plano de existência, outra forma - branca, hetero, moderna, cristã, capitalista - lhes é imposta como única alternativa viável, ontologicamente. Desta forma, seu lugar na academia será sempre de objeto, de relegado, de renegado, de excluído, de falseado, de naturalizado. Faz parte desta colonização epistêmica, praticada pela academia e pelos sistemas de poder articulados nela (e para ela) fazer com que o colonizado se isole, dos outros e de si. Os livros e aulas falam dele e por ele, nunca para ele, partindo dele ou com ele. Ele não se reconhece mais nem em si, nem nas divagações e reflexões academicamente hegemônicas sobre ele. É um processo efetivo de esvaziamento de si.

Como romper com isso? O primeiro passo, já mencionado aqui é, certamente, o reconhecimento de que tal sistema de invisibilidade do outro é parte inerente às relações coloniais e de colonialismo acadêmico. Mister é apontar aqui que várias têm sido as chaves interpretativas que apontam para isso - como os pós-colonialismos e a decolonialidade - mas, ainda assim, quase sempre com um viés verticalizado e de fora para dentro (ainda que, às vezes, bem-intencionado). Desta maneira, à incorporação desse conjunto de novos atores e agentes nas universidades deve se seguir uma revisão de práticas institucionais, hierarquizantes, ególatras e tão bem consolidadas 


\section{Colonialismo, Saberes e Fronteiras epistêmicas}

(posto que replicam, tal qual imagem narcisista) o ethos acadêmico hegemônico.

Mesmo o conceito de inclusão, em nossos contextos intelectuais e acadêmicos deve ser repensada (e dispensada). Incluir, sim; integrar ou assimilar, não. Integrar ou assimilar implica em matar a pluriversidade de perspectivas e potencialidades epistemopolíticas desses atores e agentes, tratando de homogeneizá-los. O que seus próprios lugares de enunciação podem fornecer em termos de críticas ao racismo, ao patriarcado, à misoginia, à heteronormatividade, etc? O que podem nos informar sobre etnicidade, subjetividade, desenvolvimento, "civilização" e "progresso"?

Mais que isso: por que caminhos passa a reconstrução de categorias identitárias ou de pertencimento rumo à desconstrução heurística de (pré)conceitos? Se as colônias são, historicamente, laboratórios das instituições e dos preceitos modernos, talvez devam e precisem ser os laboratórios da antimodernidade, do anti-euronorcentrismo, do anti-ocidentalismo, do antipatriarcado... Neste processo de ampliação dos saberes, não se busca a negação pela negação da "ciência moderna", mas a utilização dela de modo contra hegemônico, permitindo a introdução da diversidade de produções de saberes que existem ao nosso redor e que possam vir a contribuir sobremaneira para um conhecimento do mundo mais plural e, por isso, mais rigoroso.

A fronteira, neste sentido, não tem aqui o sentido já tão desgastado por páginas e mais páginas de reflexões - muitas vezes áridas - mas o de uma potência. De um espaço de trânsitos de saberes e de resistência às formas constituídas de saberes instituídos que não nos representam. De usar outras redes e outros espaços para consolidar conhecimentos-outros desde outras epistemes. 